\title{
Assessment of Risk Factors Associated with Severe Acute Malnutrition Among Children Admitted to Arsi Zone Gov'tal Hospitals, Ethiopia, 2016: Cross Sectional Study
}

\author{
Tolessa Kebede Bedo", Birhanu Alemu Feseha \\ Department of Nursing, College of Health Sciences, Arsi University, Asella, Ethiopia \\ Email address: \\ tolessakebede12@gmail.com (T. K. Bedo), birhanualemu02@yahoo.com (B. A. Feseha) \\ ${ }^{*}$ Corresponding author
}

\section{To cite this article:}

Tolessa Kebede Bedo, Birhanu Alemu Feseha. Assessment of Risk Factors Associated with Severe Acute Malnutrition Among Children Admitted to Arsi Zone Gov'tal Hospitals, Ethiopia, 2016: Cross Sectional Study. International Journal of Clinical and Experimental Medical Sciences. Vol. 6, No. 4, 2020, pp. 51-59. doi: 10.11648/j.ijcems.20200604.11

Received: May 21, 2020; Accepted: June 10, 2020; Published: July 6, 2020

\begin{abstract}
Background Malnutrition remains one of the most common causes of morbidity and mortality among children throughout the world. It is responsible about $60 \%$ cause of death in under age of 5 years. Objective To assess feeding practice and factors associated with severe acute malnutrition in under age of 5 year children admitted to Arsi zone public Hospitals, Ethiopia, 2016. Methods and Materials A cross sectional study design was conducted from July 2014 to June 2016 on age of 5 years children admitted to Arsi Zone Governmental Hospitals. The required number of samples was selected based on the registration and diagnosis. Data was collected by review of medical records and interview of the family member nearby during data collection. The data was manipulated and analyzed by using Epi. info version 3.5.4 for windows and Statistical Package for Social Sciences (SPSS) version 16.0. Results Out of one hundred fifty-one study subjects, $124(82.1 \%)$ of them breastfed; but majority of them, $65.4 \%$ did not practice exclusive breast feeding. Maternal illiteracy had 2.46 times high risk and significant association with severe acute malnutrition ( $\mathrm{AOR}=2.46,95 \% \mathrm{CI}, 1.4-42.4)$. Being age younger than 11 months also showed 5.97 times high risk and statistically significant association with severe acute malnutrition (AOR=5.97, 95\% CI, 1.820). Children of governmental employee mother were 2.29 times high risk to be affected by marasmus ( $\mathrm{AOR}=2.29,95 \% \mathrm{CI}$, 1.4-3.86). Male children were 2.28 times higher risk to be affected by the case than female children ( $\mathrm{AOR}=2.28,95 \% \mathrm{CI}, 1.1-$ 4.9).
\end{abstract}

Keywords: Malnutrition, Diarrheal Disease, Marasmus, Bottle Feeding

\section{Introduction}

Malnutrition is a pathological state resulting from inadequate nutrition. It is broadly classified as under nutrition, as a result of insufficient intake of energy and other nutrients, and over nutrition due to excessive consumption of energy and other nutrients [1]. Severe acute malnutrition (SAM) is defined by a very low weight for height (below $-3 \mathrm{z}$ scores of the median WHO growth standards), by visible severe wasting, or by the presence of nutritional edema [2].

Malnutrition remains one of the most common causes of morbidity and mortality among children throughout the world [3]. Particularly stunting, is still a severe public health problem in Sub Saharan Africa [4]. For example, about 35\% of preschoolers are stunted; while $29 \%$ are underweight in Sub-Saharan Africa [5]. In addition, the Fifth Global Nutritional Report estimates that in East Africa 44\% of children under-five were stunted while $31 \%$ were underweight in 2005 [6]. It has been responsible, directly or indirectly, for $60 \%$ of the 10.9 million deaths annually among children under five [6]. Malnutrition has both short term and long-term adverse ramifications. In the short-term for the individual, it is associated with illness, health and mortality [7].

In the long-term, it leads to impaired cognitive 
development, poor educational achievement and economic productivity [8-9]. Poverty and ignorance play important roles at the background in the causation of malnutrition especially in the developing world. Poor feeding practices have been identified in the developing world to arise from ignorance about adequate breastfeeding and appropriate weaning practices. All these are closely related to the socioeconomic status and sizes of families [10]. Individuals from low socio-economic backgrounds and particularly those living in poverty are more likely to be malnourished than individuals from higher socio-economic classes. This is most often primary malnutrition as a result of food insecurity [11].

Secondary malnutrition is also more prevalent in situations of poverty due to overcrowding and poor sanitation (which for example increase the risk of infection) and contributes to the increased incidence of malnutrition amongst the poor. History of recent infectious and parasitic disease, in particular diarrhea, malaria, or intestinal worms predisposes an individual to malnutrition and these conditions reduce the proportion of nutrients which the body is able to consume [12].

\section{Methods and Materials}

A cross-sectional study was conducted in Arsi Zone Governmental Hospitals to assess risk factors associated with SAM among children admitted with severe acute malnutrition from July 2014 to June 2016.

All children admitted to hospital with severe acute malnutrition before and during data collection were included as study participant based on their registration documented in registration book. The independent variables are socio demographic characteristics like age, sex, religion, ethnicity, education, occupation, marital status, family size and monthly income. Clinical and anthropometric information such as previous illnesses: infections, diarrhea, acute respiratory infection, HIV/AIDS and feeding practice.

The structured questionnaire was translated to Amharic languages and the questionnaire was pretested on 15 children admitted with SAM to Asella Hospital. Training was given for three supervisors (Bachelor Nurses) and six data collectors (Diploma Nurses and Bachelor Nurses) and included provision of handouts on a review of general study objectives and procedures, detailed discussion of every data item to be collected and discussion of how to resolve potential problems, practical session on measurement and observations based on standard way.

Data was entered to Epi-Info 3.5.4 for windows and analyzed using SPSS version 16.0 for windows. The data was double entered to check the consistency. The data was cleaned and edited before analysis. Data exploration was undertaken to see if there were odd codes or items that were not logical and then subsequent editing was made.

Followed the approval by Institutional Research and
Publication office, Official letter of co-operation was written to the concerned bodies. As the study was conducted through review of medical records and non invasive data collection methods, the individual patients were not subjected to any harm as far as the confidentiality was kept. No personal identifiers were used on data collection form. The recorded data was not accessed by a third person except the principal investigator, and was kept confidentially.

\section{Results}

The total sample size included in the study was 151 subjects. All the study subjects provided their relevant information which making the response rate $100 \%$. The mean age of the mother's is 27.99 with Standard deviation of 4.76 . Concerning educational status of the mother's 57 (37.7\%) were educated to grade 1-8, $29(19.2 \%)$ can read and write, $28(18.5 \%)$ were attended grade 9-12, 26 (17.2\%) have no formal education (illiterate), and $11(7.3 \%)$ were complete College/University. When considering occupational status of the mother's, most of them were daily labor workers 65 (43\%), $46(31.8 \%)$ were house wife, 21 (13.9\%) were merchant, 9 (6\%) were governmental employee and 8 (5.3\%) were private workers (Table 1).

Most of the study subjects' fathers were attended grade 18, $53(43.4 \%), 32(25.4 \%)$ were completed grade 9-12, 21 $(17.2 \%)$ were attended college/University, 10 (8.2\%) can read and write and $7(5.7 \%)$ have no formal education (illiterate). Regarding occupational status of study subject's fathers, $60(49.2 \%)$ were daily labors, 26 (21.3\%) were merchant, $20(16.4 \%)$ were private worker and $16(13.1 \%)$ were governmental workers (Table 1). Regarding the ethnic group of the study subjects, 46 (30.5\%) were Oromo, 45 (29.8\%) were Amhara, 26 (17.2\%) were Tigre, 25 (16.6\%) were Gurage and $9(6 \%)$ were others. Of 151 study subjects, 96 (63.6\%) were Orthodox, 28 (18.5) were Protestant and the remaining $27(17.9 \%)$ were Muslims. (Table 1).

Monthly income of most of the study subjects' family ranges from 500-1000 Birr which accounts 59 (39.1\%), < 500 Birr accounts 29 (19.2\%), 1600- 2000 Birr accounts 22 (14.6\%), >2000 Birr accounts 21 (13.9\%) and 1100-1500 Birr accounts $20(13.2 \%)$ (Table 1). Regarding the family size of the study subjects, $63(41.7 \%)$ has 4 members, 34 $(22.5 \%)$ has 5 members, $31(20.5 \%)$ has 3 members, 13 $(8.6 \%)$ has 2 members and $10(6.6 \%)$ has $>5$ members. The number of under age of 5 years children in the family is one in most of the study subjects which is 134 (88.7\%), 14 $(9.3 \%)$ has 2 and $3(2 \%)$ has $>2$ under age of 5 years children (Table 1). Regarding the child's socio demographic status, 73 (48.3) of them were 11 and younger than 11 months, 61 (40.4) were 12-23 months and the remaining 17 (11.3) were 24 to 59 months old. Out of 151 study subjects, 89 (58.9) were male and 62 (41.1) were female (Table 1). 
Table 1. Socio demographic characteristics of the family and the child of the children admitted with SAM to Arsi Zone Governmental Hospitals, 2016.

\begin{tabular}{|c|c|c|c|}
\hline & Characteristics & Frequency & Percent \\
\hline \multirow[t]{3}{*}{ Age of mothers } & $20-24$ & 31 & 20.5 \\
\hline & $25-29$ & 69 & 45.7 \\
\hline & $30+$ & 51 & 33.8 \\
\hline \multirow[t]{5}{*}{ Ethnic Group } & Amhara & 45 & 29.8 \\
\hline & Oromo & 46 & 30.5 \\
\hline & Tigry & 26 & 17.2 \\
\hline & Gurage & 25 & 16.6 \\
\hline & Others & 9 & 6.0 \\
\hline \multirow[t]{3}{*}{ Religion } & Orthodox & 96 & 63.6 \\
\hline & Muslim & 27 & 17.9 \\
\hline & Protestant & 28 & 18.5 \\
\hline \multirow[t]{5}{*}{ Mother's educational status } & Illiterate & 26 & 17.2 \\
\hline & Can read and write & 29 & 19.2 \\
\hline & Grade 1-8 & 57 & 37.7 \\
\hline & Grade $9-12$ & 28 & 18.5 \\
\hline & College/University & 11 & 7.3 \\
\hline \multirow[t]{5}{*}{ Mother's occupation } & House wife & 48 & 31.8 \\
\hline & Government employee & 9 & 6.0 \\
\hline & Merchant & 21 & 13.9 \\
\hline & Daily worker & 65 & 43.0 \\
\hline & Private worker & 8 & 5.3 \\
\hline \multirow[t]{4}{*}{ Marital status } & Single & 4 & 2.6 \\
\hline & Married & 122 & 80.8 \\
\hline & Divorced & 22 & 14.6 \\
\hline & Widowed & 3 & 2.0 \\
\hline \multirow[t]{6}{*}{ Father's education } & Illiterate & 7 & 5.7 \\
\hline & Can read and write & 10 & 8.2 \\
\hline & Grade 1-8 & 53 & 43.4 \\
\hline & Grade 9-12 & 31 & 25.4 \\
\hline & College/University & 21 & 17.2 \\
\hline & Total & 122 & 100.0 \\
\hline \multirow[t]{4}{*}{ Father's occupation } & Government employee & 16 & 13.1 \\
\hline & Merchant & 26 & 21.3 \\
\hline & Daily labor & 60 & 49.2 \\
\hline & Private work & 20 & 16.4 \\
\hline \multirow[t]{5}{*}{ Monthly income } & $<500$ Birr & 29 & 19.2 \\
\hline & 500-1000 Birr & 59 & 39.1 \\
\hline & 1100-1500 Birr & 20 & 13.2 \\
\hline & 1600-2000 Birr & 22 & 14.6 \\
\hline & $>2000$ Birr & 21 & 13.9 \\
\hline \multirow[t]{5}{*}{ Family size } & 2 & 13 & 8.6 \\
\hline & 3 & 31 & 20.5 \\
\hline & 4 & 63 & 41.7 \\
\hline & 5 & 34 & 22.5 \\
\hline & $>5$ & 10 & 6.6 \\
\hline \multirow[t]{3}{*}{ Number of children 0-59 months in the family } & 1 & 134 & 88.7 \\
\hline & 2 & 14 & 9.3 \\
\hline & $>2$ & 3 & 2.0 \\
\hline \multirow[t]{2}{*}{ Age in months } & $0-11$ & 73 & 48.3 \\
\hline & $12-23$ & 61 & 40.4 \\
\hline \multirow{4}{*}{ Sex } & $24-59$ & 17 & 11.3 \\
\hline & Male & 89 & 58.9 \\
\hline & Female & 62 & 41.1 \\
\hline & Total & 151 & 100.0 \\
\hline
\end{tabular}

Out of one hundred fifty one children diagnosed with severe acute malnutrition and admitted to hospitals 97 $(64.2 \%)$ were marasmic cases, 30 (19.9\%) were kwashiorkor and the remaining $24(15.9 \%)$ were mixed type of malnutrition (marasmic-kwash) (Table 2). One of the criteria to classify an admitted child with severe acute malnutrition is bilateral edema. Out of one hundred fifty one children admitted with the case, 98 (64.9\%) had no edema, 27 $(17.9 \%)$ had grade II edema $(++), 19(12.6 \%)$ had grade III edema $(+++)$ and the remaining $7(4.6 \%)$ had grade I edema $(+)$ when they admitted to the Hospital (Table 2). admitted to the hospitals (Table 2). 

Among Children Admitted to Arsi Zone Gov'tal Hospitals, Ethiopia, 2016: Cross Sectional Study

Table 2. Degree of bilateral edema on admission and different form of SAM diagnosed among children admitted to AA governmental hospitals, 2016.

\begin{tabular}{|c|c|c|c|}
\hline & & Frequency & Recent \\
\hline \multirow[t]{4}{*}{ Types of malnutrition } & Kwashiorkor & 30 & 19.9 \\
\hline & Marasmus & 97 & 64.2 \\
\hline & Marasmic-kwash & 24 & 15.9 \\
\hline & Total & 151 & 100.0 \\
\hline \multirow[t]{5}{*}{ Degree of bilateral edema on admission } & 0 & 98 & 64.9 \\
\hline & + & 7 & 4.6 \\
\hline & ++ & 27 & 17.9 \\
\hline & +++ & 19 & 12.6 \\
\hline & Total & 151 & 100.0 \\
\hline
\end{tabular}

Regarding weight for height condition on admission, $96(63.6 \%)$ were $<60 \%, 30(19.9 \%)$ were $>=80 \%$ and the rest 25 $(16.6 \%)$ were between $60-80 \%$. Concerning about MUAC on admission $105(69.5 \%)$ were less than $11.5 \mathrm{~cm}$ and $46(30.5 \%)$ were greater than or equal to $11.5 \mathrm{~cm}$ (Figure 1).

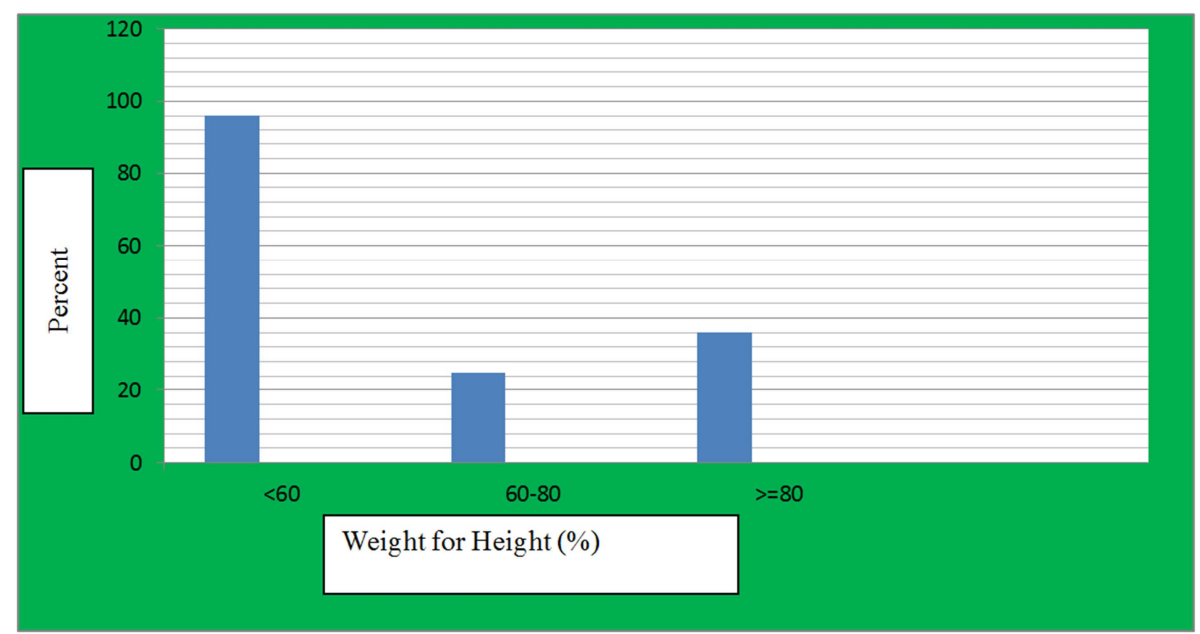

Figure 1. Weight for height status on admission of children admitted with different form of SAM to Arsi Zone governmental hospitals, 2016.

Out of one hundred fifty one study subjects, 64 (42.4\%) of them reported different cases that they have experienced in a month before the study. They have reported more than one case they have experienced in the past. $35(54.7 \%)$ of them reported history of severe vomiting, $45(70.3 \%)$ reported history of fever, 41 (64.1\%) reported history of diarrhea, 17 (26.6\%) reported history of pneumonia and 27 (42.9\%) reported history of chronic illnesses like heart disease, Tuberculosis, and spinal cord defect (Figure 2).

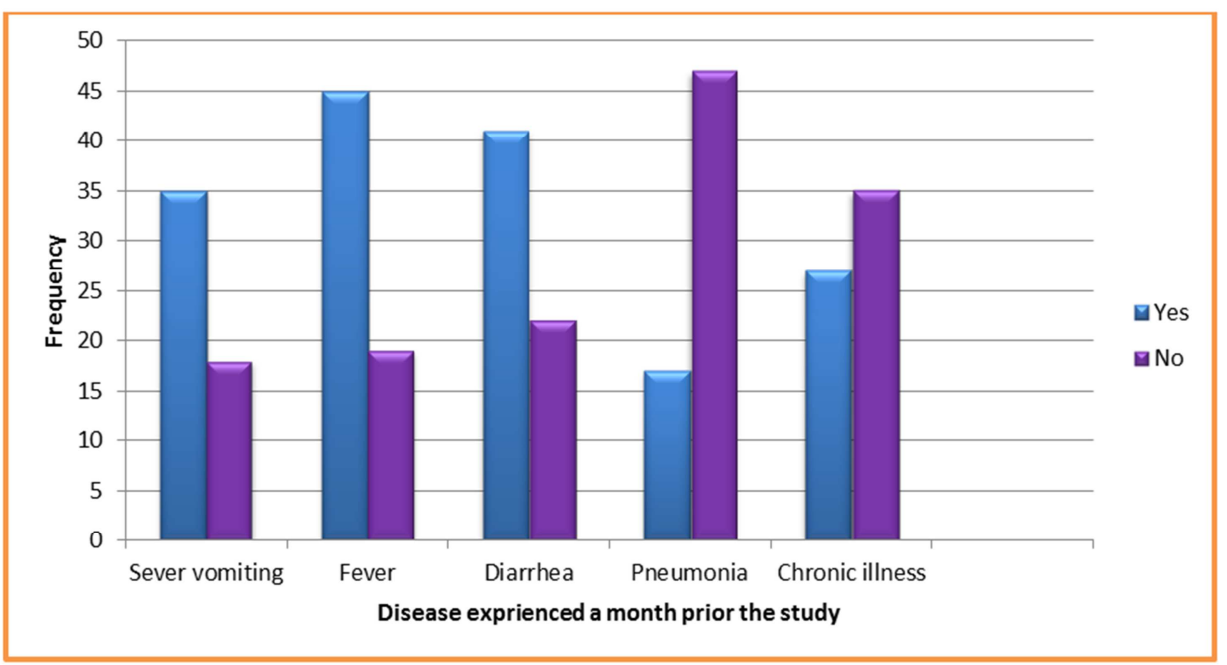

Figure 2. History of cases experienced a month prior the study by children admitted with SAM to Arsi Zone governmental hospitals, 2016.

Concerning HIV status of the study subjects, 105 (69.5\%) of them were non reactive, $44(29.2 \%)$ were unknown result and 2 $(1.3 \%)$ were reactive (Figure 3$)$. 


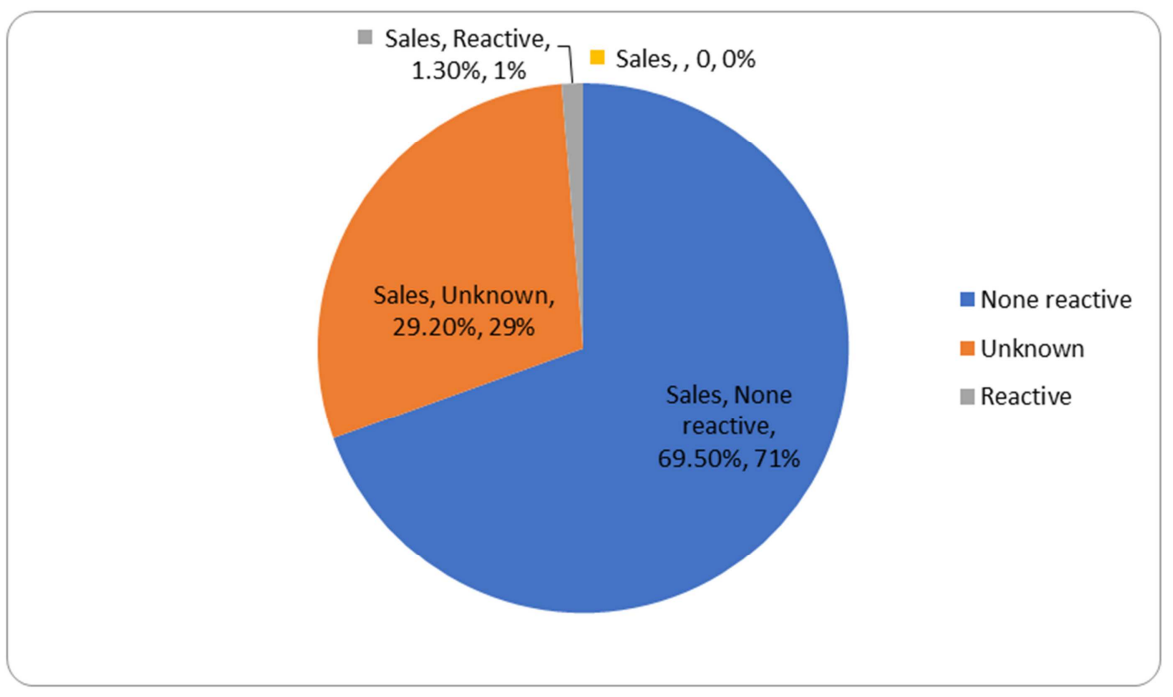

Figure 3. HIV status of children admitted with SAM to Arsi Zone governmental hospitals, 2016.

Regarding breast feeding practice, most of the study subjects have fed breast milk since their birth which accounts $124(82.1 \%)$ and the remaining $27(17.9 \%)$ did not feed breast milk instead they have fed formula milk. Those children who have got breast milk, fed for vary duration in time. $77(62.1 \%)$ of them fed for 7-12 months, $21(16.9 \%)$ fed for $>12$ months, $15(12.1 \%)$ fed for $4-6$ months and 11 $(8.9 \%)$ fed for $<4$ months (Table 3 ).

Table 3. Duration of breast feeding among children admitted with SAM to Arsi Zone governmental hospitals, 2016.

\begin{tabular}{lll}
\hline Age & Frequency & Percent \\
\hline$<4$ months & 11 & 8.9 \\
$4-6$ months & 15 & 12.1 \\
$7-12$ months & 77 & 62.1 \\
$>12$ months & 21 & 16.9 \\
Total & 124 & 100.0 \\
\hline
\end{tabular}

Out of children who have got breast milk, 107 (86.3\%) of them have started additional food other than breast milk. Most of them started before the age of 6 months which accounts $70(65.4), 30(28.1 \%)$ started at the age of 6 months, $6(5.6 \%)$ started between the age of 7-12 months and 1 $(0.9 \%)$ started after 12 months old (Figure 4$)$.

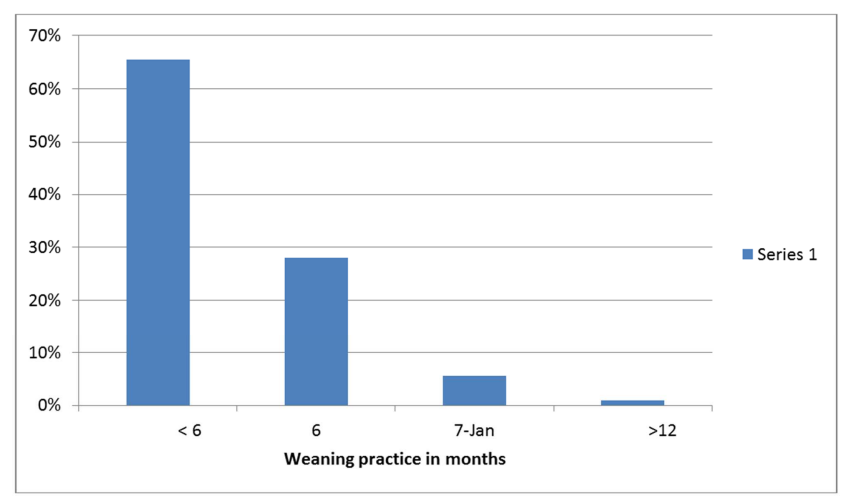

Figure 4. Weaning practice among children admitted with SAM to Arsi Zone governmental hospitals, 2016.
Out of one hundred thirty four children who are currently on feeding other than breast milk and/or breast milk, 98 $(73.1 \%)$ are fed by mothers or fathers, $20(14.9 \%)$ are fed by siblings and $16(12.0 \%)$ are fed by others like grandmother. Regarding the means of feeding foods other than breast milk, $115(85.8 \%)$ are used bottle feeding, $14(10.5 \%)$ are used cup and $5(3.7 \%)$ are used spoon to feed the child (Figure 5).

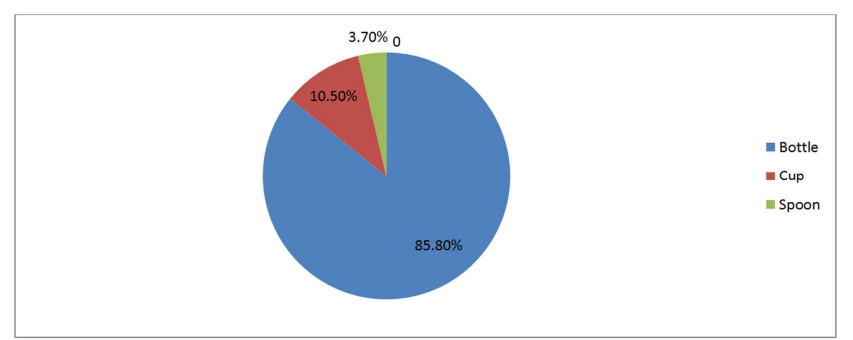

Figure 5. Means of feeding foods other than breast milk among children admitted with SAM to Arsi Zone governmental hospitals, 2016.

From the table of association below, 55 of children 11 months and younger were marasmic. These age group is 4.37 times high risk to be affected by marasmus and has statistically significant association at $(\mathrm{COR}=4.37,95 \% \mathrm{CI}$, 1.45-13.15). Further adjustment for other variables by multinomial logistic regression again shows that these age group is 5.97 times high risk to be affected by the case which indicate stronger association between these variables and statistically significant association at $(\mathrm{AOR}=5.97,95 \% \mathrm{CI}$, 1.8 - 20) (Table 4). Regarding the sex, the risks of male children being marasmic relative to female children were high: 1.99 times of female children and has statistically significant association at $(\mathrm{COR}=1.99,95 \% \mathrm{CI}, 1.01-3.93)$; and adjustment with other variables by multinomial logistic regression indicates 2.28 times high risk male children affected than female children and has statistically significant association at $(\mathrm{AOR}=2.28,95 \% \mathrm{CI}, 1.1-4.9)$ (Table 4). When concerning maternal education, children from illiterate mothers were 5.04 times affected by marasmus and has statistically significant association at $(\mathrm{COR}=5.04,95 \% \mathrm{CI}$, 
1.09-234). Further adjustment also shows greater association and significance $(\mathrm{AOR}=2.46,95 \% \mathrm{CI}, 1.4-42.4)$ (Table 4). Children of governmental employee mother were 1.15 times affected by marasmus form of SAM and has statistically significant association at $(\mathrm{COR}=1.1595 \% \mathrm{CI}, 1.12-9.89)$; then further adjustment also shows more strength and significant association at $(\mathrm{AOR}=2.29,95 \% \mathrm{CI}, 1.4-3.86)$ (Table 4).

Table 4. Risk factors associated with marasmus among children admitted with SAM to AA public hospitals, 2014.

\begin{tabular}{|c|c|c|c|c|c|c|}
\hline \multirow{2}{*}{ Variables } & \multicolumn{6}{|c|}{ Marasmus } \\
\hline & Yes \% & No $\%$ & p-value & $\operatorname{COR}(95 \% \mathrm{CI})$ & p-value & $\operatorname{AOR}(95 \% \mathrm{CI})$ \\
\hline \multicolumn{7}{|c|}{ Age of child (months) } \\
\hline $0-11$ & $55(75.3)$ & $18(24.7)$ & 0.009 & $4.37(1.45-13.15)^{*}$ & & \\
\hline $12-23$ & $35(57.4)$ & $6(42.6)$ & 0.24 & $1.92(0.65-5.72)$ & 0.004 & $5.97(1.8-20)^{* *}$ \\
\hline $24-59$ & $7(41.2)$ & $10(58.8)$ & & & & \\
\hline \multicolumn{7}{|l|}{ Sex } \\
\hline Male & $63(70.8)$ & $26(29.2)$ & 0.046 & $1.99(1.01-3.93)^{*}$ & 0.035 & $2.28(1.1-4.9)^{* *}$ \\
\hline Female & $34(54.8)$ & $28(45.2)$ & & & & \\
\hline \multicolumn{7}{|l|}{ Age of mother (yrs) } \\
\hline $20-24$ & $22(71.0)$ & $9(29.0)$ & 0.447 & $1.45(0.56-3.79)$ & & \\
\hline $25-29$ & $43(62.3)$ & $26(37.7)$ & & $0.98(0.46-2.07)$ & & \\
\hline $30+$ & $32(62.7)$ & $19(37.3)$ & & & & \\
\hline \multicolumn{7}{|l|}{ Mother Education } \\
\hline Illiterate & $21(80.8)$ & $5(19.2)$ & 0.039 & $5.04(1.09-23.4)^{*}$ & \multirow{5}{*}{0.028} & \multirow{5}{*}{$2.46(1.4-42.4)^{* *}$} \\
\hline Can read \& write & $19(65.5)$ & $10(34.5)$ & 0.253 & $2.28(0.56-9.36)$ & & \\
\hline Grade $1-8$ & $33(57.9)$ & $24(42.1)$ & 0.450 & $1.65(0.45-6.04)$ & & \\
\hline Grade 9-12 & $19(67.9)$ & $9(32.1)$ & 0.202 & $2.53(0.61-10.56)$ & & \\
\hline College/University & $5(45.5)$ & $6(54.5)$ & & & & \\
\hline \multicolumn{7}{|l|}{ Father Education } \\
\hline Illiterate & $4(57.1)$ & $3(42.9)$ & 0.650 & $0.67(0.12-3.84)$ & \multirow{11}{*}{0.030} & \multirow{11}{*}{$2.29(1.4-38.6)^{* *}$} \\
\hline Can read \& write & $9(90.0)$ & $1(10.0)$ & 0.191 & $4.5(0.47-42.97)$ & & \\
\hline Grade $1-8$ & $33(62.3)$ & $20(37.7)$ & 0.723 & $0.83(0.29-2.39)$ & & \\
\hline Grade 9-12 & $15(48.4)$ & $16(51.6)$ & 0.196 & $0.47(0.15-1.48)$ & & \\
\hline College/University & $14(66.7)$ & $7(33.3)$ & & & & \\
\hline Mother occupation & & & & & & \\
\hline Housewife & $27(56.2)$ & $21(43.8)$ & 0.119 & $3.86(0.71-21.09)$ & & \\
\hline Gov't employee & $7(77.8)$ & $2(22.2)$ & 0.040 & $1.15(1.12-9.89)^{*}$ & & \\
\hline Merchant & $16(76.2)$ & $5(23.8)$ & 0.019 & $9.6(1.45-63.5)^{*}$ & & \\
\hline Daily labor & $45(69.2)$ & $20(30.2)$ & 0.026 & $6.75(1.25-36.4)^{*}$ & & \\
\hline Private worker & $2(25.0)$ & $6(75.0)$ & & & & \\
\hline \multicolumn{7}{|l|}{ Father occupation } \\
\hline Gov't employee & $9(56.2)$ & $7(43.8)$ & 0.821 & $0.86(0.23-3.25)$ & & \\
\hline Merchant & $20(76.9)$ & $6(23.1)$ & 0.221 & $2.22(0.62-7.97)$ & & \\
\hline Daily labor & $34(56.7)$ & $26(43.3)$ & 0.794 & $0.87(0.31-2.44)$ & & \\
\hline Private worker & $12(60.0)$ & $8(40.0)$ & & & & \\
\hline \multicolumn{7}{|l|}{ Marital status } \\
\hline Single & $3(75.0)$ & $1(25.0)$ & 0.287 & $6(0.22-162.53)$ & & \\
\hline Married & $75(61.5)$ & $47(38.5)$ & 0.349 & $3.2(0.28-36.18)$ & & \\
\hline Divorced & $18(81.8)$ & $4(18.2)$ & 0.102 & $9(0.65-125.32)$ & & \\
\hline Widowed & $1(33.3)$ & $2(66.7)$ & & & & \\
\hline \multicolumn{7}{|l|}{ Monthly income } \\
\hline$<500$ birr & $18(62.1)$ & $11(37.9)$ & 0.726 & $1.23(0.91-3.85)$ & & \\
\hline 500-1000 birr & $38(64.4)$ & $21(35.6)$ & 0.556 & $1.36(0.49-3.75)$ & & \\
\hline $1100-1500$ birr & $13(65.0)$ & $7(35.0)$ & 0.607 & $1.39(0.39-4.92)$ & & \\
\hline $1600-2000$ birr & $16(72.7)$ & $6(27.3)$ & 0.287 & $2(0.56-7.16)$ & & \\
\hline$>2000$ birr & $12(57.1)$ & $9(42.9)$ & & & & \\
\hline \multicolumn{7}{|l|}{ Family size } \\
\hline$<4$ & $28(63.6)$ & $16(36.4)$ & 0.921 & $0.96(0.46-2.0)$ & & \\
\hline$>=4$ & $69(64.5)$ & $38(35.5)$ & & & & \\
\hline Previous illness & & & & & & \\
\hline Yes & $34(54.0)$ & $29(46.0)$ & 0.027 & $0.47(0.24-0.92)^{*}$ & & \\
\hline No & $63(71.6)$ & $25(28.4)$ & & & & \\
\hline Severe vomiting & & & & & & \\
\hline Yes & $17(48.6)$ & $18(51.4)$ & 0.282 & $0.58(0.21-1.57)$ & & \\
\hline No & $18(62.1)$ & $11(37.9)$ & & & & \\
\hline Fever & & & & & & \\
\hline Yes & $27(60.0)$ & $18(40.0)$ & 0.192 & $2.1(0.69-6.13)$ & & \\
\hline No & $8(42.1)$ & $11(57.9)$ & & & & \\
\hline Diarrhoea & & & & & & \\
\hline Yes & $22(53.7)$ & $19(46.3)$ & 0.825 & $0.89(0.32-2.49)$ & & \\
\hline
\end{tabular}




\begin{tabular}{|c|c|c|c|c|c|c|}
\hline \multirow{2}{*}{ Variables } & \multicolumn{6}{|c|}{ Marasmus } \\
\hline & Yes \% & No \% & p-value & COR $(95 \%$ CI $)$ & p-value & AOR $(95 \%$ CI $)$ \\
\hline No & $13(56.5)$ & $10(43.5)$ & & & & \\
\hline \multicolumn{7}{|l|}{ Pneumonia } \\
\hline Yes & $12(70.6)$ & $5(29.4)$ & 0.130 & $2.5(0.76-8.23)$ & & \\
\hline No & $23(48.9)$ & $24(51.1)$ & & & & \\
\hline \multicolumn{7}{|c|}{ Chronic illnesses } \\
\hline Yes & $12(44.4)$ & $15(55.6)$ & 0.191 & $0.51(0.19-1.40)$ & & \\
\hline No & $22(61.1)$ & $14(38.9)$ & & & & \\
\hline \multicolumn{7}{|l|}{ Breast feed } \\
\hline Yes & $78(63.4)$ & $45(36.6)$ & 0.658 & $0.82(0.34-1.97)$ & & \\
\hline No & $19(67.9)$ & $9(32.1)$ & & & & \\
\hline \multicolumn{7}{|c|}{ Weaning practice } \\
\hline$<6$ months & $53(69.7)$ & $23(30.3)$ & 0.157 & $1.62(0.83-3.18)$ & & \\
\hline 6 months & $24(52.2)$ & $22(47.8)$ & 0.042 & $0.48(0.24-0.98)^{*}$ & & \\
\hline 7-12 months & $5(50.0)$ & $5(50.0)$ & & & & \\
\hline$>12$ months & $1(100.0)$ & & & & & \\
\hline \multicolumn{7}{|c|}{ Means of feeding } \\
\hline Bottle & $74(64.3)$ & $41(35.5)$ & 0.247 & $1.8(0.66-4.9)$ & & \\
\hline Cup & $7(50.0)$ & $7(50.0)$ & & & & \\
\hline Spoon & $3(50.0)$ & $2(50.0)$ & & & & \\
\hline
\end{tabular}

Note: *Significant association by binary logistic regression.

**Significant association by multinomial logistic regression.

\section{Discussion}

According to nutrition baseline survey report for the national nutrition program of Ethiopia, 12 percent of children aged 6 to 59 months were wasted and three percent of them were severely wasted [32]. Many studies conducted in different countries justified that maternal literacy, family income; family size, previous illness and feeding practice are the factors either directly or indirectly affecting child nutritional status. Therefore, conducting this study is mandatory to dig out which one of this factor contributes to the occurrence of severe acute malnutrition among the study subjects. Educational level of mother is important because educated mothers are more knowledgeable about their children's health and nutrition. They can make better use of health services, provide better care, have better hygienic practices and also have higher status in the family [32]. Being age 11 months or younger increased the risk of severe acute malnutrition as shown strong association in this study.

But reason why being male child predispose to the case is unclear which needs further investigation. In this study, many of the study subjects were reported more than one past illness they have been experienced a month prior to the study. But there is no significant association shown with severe acute malnutrition in case of this study. The reason behind is the difference of study subjects, severity of the case and duration of the diseases they have been experienced. The study conducted in Nigeria indicated that the risk of severe acute malnutrition among children who have experienced malaria, diarrhea and respiratory diseases was higher [34]. Though, most of the children $(82.1 \%)$ were breastfed, $65.4 \%$ of them have been started complementary feeding before the age of six months. According to WHO recommendation the child should be exclusively feed breast milk for the first six months of life. Regarding means of feeding foods other than breast milk, however, there is no significant association between severe acute malnutrition and means of feeding in this study; most of the study subjects' family, $(85.8 \%)$ used bottle feeding which increases the risk of malnutrition and other diseases. Many studies showed that bottle-feeding should be discouraged at any age because it is usually associated with increased risk of illness, and especially diarrheal disease, because of the hygienic problem which is difficulty in sterilizing the nipples properly. It also shortens the period of postpartum amenorrhea and increases the risk of pregnancy $[18,27]$.

\section{Conclusion and Recommendation}

Although, most of the variables analyzed in this study did not show statistically significant association with the outcome variable, maternal education, maternal occupation, sex of the child being male and age of the child younger than 11 months have strong and statistically significant association with child sever acute malnutrition with child severe acute malnutrition.

The Ministry of Health in collaboration with Ministry of Education should be encouraged maternal education because it plays a vital role in child care, and feeding. Ministry of Health should be provided education concerning appropriate means of feeding and exclusive breast feeding practice at each level in the community. The respective hospitals where the data was collected should be provided health education for mothers visiting hospitals about exclusive breast feeding and appropriate feeding of complementary food. Oromia Health Bureau should arrange training program for mothers on the way of child feeding to improve child nutritional status.

\section{List of Abbreviations}

AIDS - acquired immunodeficiency syndrome 


\author{
EDHS - Ethiopian Demographic Health Survey \\ ETB - Ethiopian Birr \\ GAM - Global Acute Malnutrition \\ Gov't - government \\ HIV - Human immune virus \\ IGME - Interagency Group for Child Mortality Estimation \\ SAM - Severe acute malnutrition \\ LMIC - Low and Middle income countries \\ MDG - Millennium development goal \\ NGO - Nongovernmental Organization \\ SNNPR - Southern Nation, Nationalities and People \\ Region \\ SPSS - Statistical package for social science \\ TFC - Therapeutic feeding center \\ UN - United Nation \\ USD - United State Dollar \\ WHO - World Health Organization
}

\section{Conflict of Interests}

The authors declare that there is no conflict of interests regarding the publication of this paper.

\section{Acknowledgements}

This study would not have been possible without the mercy of our Heavenly Father God, who gave me the strength, courage and perseverance to complete this study paper. My gratitude and sincere thanks expressed to the following people and organizations. Without their support this study could not have been possible: Arsi university college health sciences for chance given me and financial support, encouragement, assistance and excellent guidance throughout the whole process of this research. My families and friends for their encouragement, support and interest on my work. Those Hospitals where the data was collected, managers, pediatrics unit staffs and study participant.

\section{References}

[1] Young H SJ. People, food and famine. 1st ed ed. London: Intermediate Technology Publications; 1995.

[2] WHO. Multicentre Growth Reference Study Group: WHO Child Growth Standards: Length/height-for-age, weight-forage, weight-for-length, weight-for-height and body mass index-for-age: Methods and development. Geneva: World Health Organization 2006.

[3] Organization WH. Management of severe malnutrition: a manual for physicians and other senior health workers. EthiopJHealth Dev. 2008; 22 (1).

[4] Stephenson LS LM, Ottesen EA. Malnutrition and parasitic helminth infections. Parasitology. 2000; 121 (suppl): S23 -38.

[5] Leenstra T PL, Kariuki SK, Oloo AJ, Kager PA, terKuile FO. Prevalence and severity of malnutrition and age at menarche; cross-sectional studies in adolescent schoolgirls in western Kenya. Eur J ClinNutr. 2005; 59 (1): 41-8.
[6] G Y. Malnutrition among children in Southern Ethiopia: levels and risk factors. Ethiop J Health Dev. 2000; 14 (3): 283-92.

[7] WHO. Reducing Risks, Promoting Healthy Life. Geneva: WHO2002.

[8] Victora CG AL, Fall C, Hallal PC, Martorell R, Richter L, Sachdev HS. Maternal and Child Undernutrition Study G: Maternal and child undernutrition: consequences for adult health and human capital. Lancet. 2008; 371 (9609): 340-57.

[9] Grantham-McGregor S CY, Cueto S, Glewwe P, Richter L, Strupp B. Developmental potential in the first 5 years for children in developing countries. Lancet. 2007; 369 (9555).

[10] HC W. Food, agriculture, and disease. Principle of Medicine in Africa. ELBS edition ed. Parry EHO1984. p. 46-103.

[11] Nations U. The Millennium Development Goals Report. New York: United Nations 2008.

[12] Elizabeth W Kimani-Murage SAN, John M Pettifor, Stephen M Tollman, Kerstin Klip stein-Grobusch, Xav ier F GómezOlivé, David B Dunger and Kathleen Kahn. Nutritional status and HIV in rural South African children. [research ]. 2011.

[13] WHO/UNICEF. WHO child growth standards and the identification of severe acute malnutrition in infants and children: Switzerland and New York, USA2009.

[14] Getaneh T AA, Tadesse Z. Protein-energy malnutrition in urban children: prevalence and determinants. Ethiop Med J. 1998; 36 (3): 153-65.

[15] Haidar J AG, Kogi-Makau W, Sorensen P. Risk factors for child under-nutrition with a human rights edge in rural villages of North Wollo, Ethiopia. East Afr med J. 2005; 82 (12): 625-30.

[16] Kikafunda JK WA, Collett D, Tumwine JK. Risk factors for early childhood malnutrition in Uganda. Pediatrics. 1998; 102 (4): 45.

[17] Sakisaka K WS, Kuroiwa C. et al. Nutritional status and associated fact ors in children aged 0-23 months in Granada, Nicaragua. 2006; 120 (5): 400-11.

[18] Odunayo SI OA. Risk factors for malnutrition among rural Nigerian children. Pac J Clin Nutr. 2006; 15 (4): 491-5.

[19] Solomon Amsalu ZT. Risk factors for severe acute malnutrition in children under the age of five: A case-control study. Ethiopia German fund for Health Dev 2008; 22 (1).

[20] Analysis of Nutrition Surveys in Ethiopia, Background Paper for workshop on contextual information collected in emergency nutrition assessments in Ethiopia, Addis Ababa 2009.

[21] Government of Ethiopia, United Nations Country Team in Ethiopia and United Nations Office for the Coordination of Humanitarian Affairs, 'Humanitarian Requirements 2011: Joint Government and Humanitarian Partners' Document', OCHA, Addis Ababa. 2011.

[22] United Nations Office for the Coordination of Humanitarian Affairs, 'Humanitarian Bulletin: Weekly humanitarian highlights in Ethiopia', OCHA, Geneva and New York, 2011.

[23] Efrem Teferi, Meskele Lera, Sahle Sita, et al,. Treatment outcome of children with severe acute malnutrition admitted to therapeutic feeding centers in Southern Ethiopia: 2010. 
[24] Central Statistical Agency [Ethiopia] and ORC Macro [USA]. Ethiopia Demographic and Health Survey 2011. Addis Ababa, Ethiopia; CSA; 2011.

[25] Nutrition baseline survey report for the National Nutrition Program of Ethiopia, Ethiopian Health and Nutrition Research Institute, 2009/10.

[26] Ethiopia National Nutrition Strategy Review and Analysis of Progress and Gaps:One Year On May. 2009.

[27] Am Shamsir A Hmed TAH, Sk R Oy, Nurul A Lam And Md I Qbal H Ossain. Determinants of Undernutrition in Children Under 2 years of Age From Rural Bangladesh. I NDIAN PEDIATRICS. 2012; 49.

[28] Benta A Abuya JCaEK-M. Effect of mother 's education on child 's nutritional status in the slums of Nairobi. BMC Pediatrics. 2012.

[29] Rayhan MI KS. Factors causing malnutrition among under five children. Pak J Nutr. 2006.
[30] CSA. [Ethiopia] and ORC Macro USA:Ethiopia Demographic and Health Survey 2011. Addis Ababa: 2012.

[31] Bahawaluddin Jamro AAJ, Shankar Lal, Ghulam Rasool Bouk, Saifullah Jamro. Risk Factors for Severe Acute Malnutrition in Children under theAge of Five Year in Sukkur. Pak J Med Res, 2012; 51 (4): 112.

[32] FMOH. National Child health policy. Nigeria: Federal Ministry of Health (FMOH). 2006.

[33] Pelletier DL FE. Changes in child survival are strongly associated with changes in malnutrition in developing countries. J Nutr 2003; 133 (1): 107-19.

[34] World Health Assembly Resolution. Infant and young child nutrition. WHA 54.2, May 2001. 38. Wang X WY, Kang C.. Feeding practices in 105 counties of rural Chaina. Child Care Health Dev. 2005; 31 (4): 417-23. 50. Bloss E WF, Bailey RC. Prevalence and predictors of underweight, stunting, and wasting among children aged 5 and under in western Kenya. J trop Pediatr. 2004; 50 (50): 260-70. 